\section{THERMOSEALING SOLUTIONS}

To help practices meet the stringent HTM 01-05 requirements, The Dental Directory offers a range of different thermosealing systems suitable for every clinical setting:

- Euroseal (GBS 702): includes transparent polycarbonate cover for better precision and an integrated support panel for improved functionality

- Euroseal 2001 Plus (GBS 700): enhanced version Euroseal with reduced dimensions, and a metal roll-locking bar for improved performance

- Tecno-Gaz 'ONE' Welding System (GBT 010): latest generation welding machine with temperature control for improved functionality and improved welding

\section{PAINLESS AND NO THICK LIPS}

General Medical's new Quicksleeper S4 delivers profound anaesthesia quickly, easily, painlessly and with no 'thick lips'. Quicksleeper enables dentists to perform osteocentral anaesthesia whereby small amounts of conventional local anaesthetic are placed in the spongy bone in between teeth. Eliminating the need for painful infiltration, block and

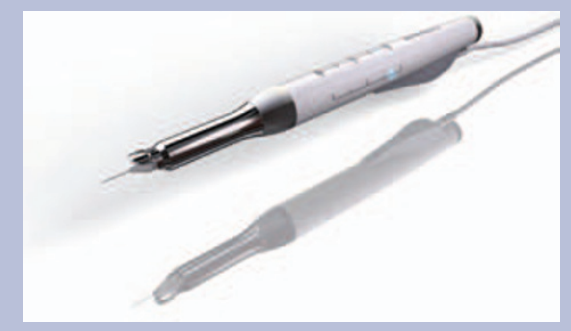

- WetH Seal2 Thermosealing System (GBW 010): transparent sealing station with integrated work surface and patented double roll holder.

Produces perfect quality $12 \mathrm{~mm}$ seals in just two seconds.

For more information, contact The Dental Directory on 0800585 586, or visit www.dental-directory.co.uk.

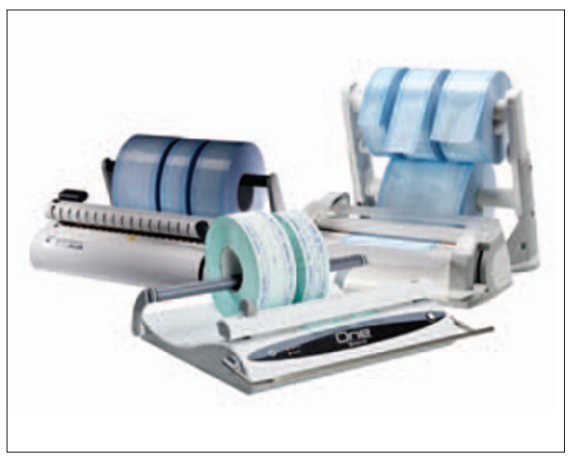

palatal injections, it delivers profound anaesthesia almost instantaneously. As it acts locally and does not create lingual anaesthesia or 'thick lips' associated with ID and mental blocks, there is no risk of patients biting their lips and it is safe to use bilaterally.

Using Quicksleeper it is possible to anaesthetise two to eight teeth with just one injection without the need for additional palatal or buccal injections - enabling more treatment to be performed per session. Completely pain-free it is effective even in the presence of pulpitis and suitable for all forms of treatment including extractions and implantology.

Call 01380 734990, visit www. generalmedical.co.uk or email info@ generalmedical.co.uk.

\section{ERADICATE WORKING POSTURE PAIN}

Ellis Paul has developed an interactive CD-Rom on Perfect posture and team dentistry in partnership with Smile-on.

The CD-Rom aims to prevent the effects of working in distorted postures such as musculoskeletal pain, physical stress, disability and loss of fine finger control. At the heart of the course is the eradication of pain.
An integral factor in perfect posture is proper use of four-handed dentistry, including seating the patient correctly, aspiration and tissue control.

If you are suffering from back or neck pain or want to use your nurse more effectively, the course is not to be missed.

For more information on the interactive CD-Rom call 02074008989 or emailinfo@smile-on.com. 